\title{
Cordia lutea L. Flowers: A Promising Medicinal Plant as Chemopreventive in Induced Prostate Carcinogenesis in Rats
}

\author{
Juan Pedro Rojas-Armas $\mathbb{D}^{1},{ }^{1}$ Jorge Luis Arroyo-Acevedo, ${ }^{1}$ José Manuel Ortiz-Sánchez, ${ }^{2}$ \\ Miriam Palomino-Pacheco, ${ }^{3}$ Oscar Herrera-Calderón $\left(\mathbb{D},{ }^{4}{ }^{J}\right.$ James Calva, ${ }^{5}$ \\ Agustín Rojas-Armas, ${ }^{6}$ Hugo Jesús Justil-Guerrero, ${ }^{1}$ Américo Castro-Luna, ${ }^{4}$ \\ and Julio Hilario-Vargas ${ }^{7}$
}

\author{
${ }^{1}$ Department of Dynamic Sciences, Laboratory of Pharmacology, Faculty of Medicine, \\ Universidad Nacional Mayor de San Marcos, Lima, Peru \\ ${ }^{2}$ Laboratory of Physiology, Faculty of Medicine, Universidad Nacional Mayor de San Marcos, Lima, Peru \\ ${ }^{3}$ Laboratory of Biochemistry, Faculty of Medicine, Universidad Nacional Mayor de San Marcos, Lima, Peru \\ ${ }^{4}$ Faculty of Pharmacy and Biochemistry, Universidad Nacional Mayor de San Marcos, Lima, Peru \\ ${ }^{5}$ Department of Chemistry and Exact Sciences, Technical Particular University of Loja, Loja, Ecuador \\ ${ }^{6}$ Instituto Regional de Enfermedades Neoplásicas, Trujillo, Peru \\ ${ }^{7}$ Department of Physiology, Faculty of Medicine, Universidad Nacional de Trujillo, Trujillo, Peru
}

Correspondence should be addressed to Oscar Herrera-Calderón; oherreracalderon@gmail.com

Received 7 April 2020; Accepted 6 May 2020; Published 26 May 2020

Guest Editor: Rômulo Dias Novaes

\begin{abstract}
Copyright (C) 2020 Juan Pedro Rojas-Armas et al. This is an open access article distributed under the Creative Commons Attribution License, which permits unrestricted use, distribution, and reproduction in any medium, provided the original work is properly cited.

The objective of this study was to evaluate the chemopreventive effect of the ethanolic extract of Cordia lutea flowers (EECL) on $\mathrm{N}$-methyl-N-nitrosourea- (MNU), cyproterone-, and testosterone-induced prostate cancer in rats. 40 Holtzman male rats were used and assigned to 5 groups $(n=8)$. In Group I, rats received normal saline $(10 \mathrm{~mL} / \mathrm{Kg})$; Group II: rats were induced for prostate cancer with cyproterone, testosterone, and NMU; Groups III, IV, and V: rats received EECL daily, at doses of 50, 250, and 500 mg/ $\mathrm{kg}$ body weight, respectively. After the period of treatment, animals were sacrificed by an overdose of pentobarbital and blood samples were collected for determination of prostate-specific antigen (PSA). The prostate was dissected and weighed accurately. The ventral lobe of the prostate was processed for histopathology analysis. The somatic prostate index decreased with EECL at dependent dose, from $0.34 \pm 0.04$ to $0.23 \pm 0.05(P<0.05)$. The PSA levels also decreased significantly at doses of 250 and $500 \mathrm{mg} /$ $\mathrm{kg}$. Histopathological analysis showed a decrease in the number of prostatic layers with high-grade prostatic intraepithelial neoplasia (HG-PIN) and low-grade prostatic intraepithelial neoplasia (LG-PIN) at the dose of $500 \mathrm{mg} / \mathrm{kg}$. The ethanolic extract of Cordia lutea flowers had a chemopreventive effect on induced prostate cancer in rats.
\end{abstract}

\section{Introduction}

Cancer is a large group of diseases that can start in almost any organ or tissue in the body when abnormal cells grow uncontrollably, go beyond their usual limits to invade adjacent parts of the body, and/or spread to other organs, the latter. This process is called metastasis and is a major cause of cancer death [1]. Population growth and increased longevity are globally increasing the number of older people; aging is associated with noncommunicable diseases (NCDs), which are responsible for seven out of every 10 deaths in the world [2]. One of the main causes of death from NCDs is cancer, which in 2018 affected 18.1 million people worldwide and produced 9.6 million deaths. Estimating by 2040, these numbers will be almost double, the largest increase being in low- and middle-income countries, where more than two-thirds of cancers in the world will occur [3]. Lung, prostate, colorectal, stomach, and liver cancer are the most common types of cancer in men, while breast, colorectal, 
lung, cervical, and thyroid cancer are the most common in women [1].

In the United States, cancer is the second leading cause of death, with $1,806,590$ new cancer cases and 606,520 cancer deaths projected in 2020, of which 191,930 will be new cases of prostate cancer causing 33,330 deaths [4]. In Peru, death rates from prostate cancer increased from 20.9 (2005-2009) to 24.1 (2010-2014) per 100,000 men, an increase of $15.2 \%$. According to the regions, during the period 2010-2014, the coast had the highest mortality rate $(28.9$ per 100,000$)$, while the rain forest had the lowest $(7.43$ per 100,000$)$ [5].

The drugs used in cancer treatment have no selectivity to destroy tumor cells and also damage nontumor cells, producing many side effects, mainly gastrointestinal, neurological, hematological, dermatological, etc. [6,7]. Furthermore, toxicity extends to people who are exposed to the chemotherapy area for job or another reason [8]. On the other hand, the cost of drugs for the treatment of prostate cancer is high [9]. This situation motivates the search for new agents with a better safety profile and lower cost. In this context, an alternative source is natural resources.

Cordia lutea (Family: Boraginaceae) is an indigenous plant of Peru, sometimes a shrub or tree, whose flowers are yellow; it is known by the common name of overo, alkka mallki, biyuyo, caujaro, gomo, yellow gomo, muercielago, or ubito. In traditional Peruvian medicine, Cordia lutea has been widely used for the treatment of hepatic disorders [10] and in northern Peru for prostate inflammation [11]. In traditional Peruvian medicine, Cordia lutea is known as "overo" flower, which have been widely used for the treatment of liver disorders and in northern Peru for prostate inflammation [11].

The phytochemical study of the flower revealed the presence of terpenic and phenolic compounds, such as flavonoids and leucoanthocyanidins, of which the majority compound was rutin [12]. Other research also reported the presence of rutin and quercetin in the whole plant as the main constituents [10]. The anticancer effect of quercetin and rutin has been reported in several animal models, retarding, inhibiting, or suppressing tumor growth [13]. This background motivated us to propose the evaluation of the chemopreventive effect of the ethanolic extract from Cordia lutea flowers on NMU-induced prostate cancer in rats.

\section{Material and Methods}

2.1. Preparation of Extract of Cordia lutea Flowers. Cordia lutea L. (C. lutea) flowers were collected in the city of Trujillo, Peru. The material was identified at the Herbarium of the National University of San Marcos, Lima, Peru. The flowers were washed, dried at $40^{\circ} \mathrm{C}$, and pulverized in an electric mill. Phytochemicals were extracted in $96 \%$ ethanol. The extract was collected, filtered, and concentrated on a rotary evaporator; finally, it was stored in aliquots and kept in freezer until further use.

\subsection{Phytochemical Analysis of Ethanol of Extract Cordia lutea.} The chemical components of the ethanol extract were analyzed on a gas chromatograph (Agilent Technologies 6890N), coupled to a mass spectrometer 5973N (Santa Clara, CA, USA) and equipped with a DB-5MS capillary column (5\% phenyl methyl silox, $30 \mathrm{~m}, 0.25 \mathrm{~mm}$ internal diameter, $0.25 \mu \mathrm{m}$ film thickness; J\&W Scientific, Folsom, CA, USA). For the separation of volatile components, the following temperature program was used: $5 \mathrm{~min}$ at $60^{\circ} \mathrm{C}, 3^{\circ} \mathrm{C} / \mathrm{min}$ up to $165^{\circ} \mathrm{C}$, and $15^{\circ} \mathrm{C} / \mathrm{min}$ up to $250^{\circ} \mathrm{C}$ and kept for $10 \mathrm{~min}$. Injector and detector temperatures were maintained at $220^{\circ} \mathrm{C}$. The carrier gas was helium, at a flow rate of $1 \mathrm{~mL} / \mathrm{min}$. The injector was operated in split mode, with a division ratio of $1: 50$. The acquisition mass range was set at $40-350 \mathrm{~m} / z$. Ionization mode: impact of electrons $(70 \mathrm{eV})$. The extract was diluted to $1: 100 \mathrm{v} / \mathrm{v}$ in dichloromethane (Fisher Scientific, $99.9 \%$ pure) and $1 \mu \mathrm{L}$ of the solution was injected [14].

2.3. Animals. Healthy male Holtzman adult rats weighing $200 \pm 20 \mathrm{~g}$ were used. The animals were purchased from the National Institute of Health, housed in polypropylene cages and air-conditioned environment with a $12 \mathrm{~h}$ light/dark cycle. They were allowed free access to drinking water throughout the experimental period. The animals were fed with standard feed for rats. The specifications and recommendations proposed by the guide for the Care and Use of Laboratory Animals were followed and in compliance with the current regulations of the Animal Protection Law (Law no. 27265) [15].

2.4. Induction of Prostate Cancer. Prostate cancer induction was carried out with carcinogen and hormone, in a sequential process that began with temporary chemical castration with cyproterone acetate, followed by prostate stimulation with testosterone propionate, and finally carcinogenesis with N-methyl-N-nitrosourea (MNU). The method of Sharmila et al. [16] and Banudevi et al. [17] was followed with slight modification; rats received cyproterone acetate $(50 \mathrm{mg} / \mathrm{kg}$ body weight in sesame oil) daily by intraperitoneal injection for 18 consecutive days; one day after the final dose of cyproterone acetate, rats received daily subcutaneous injections of testosterone propionate $(100 \mathrm{mg} / \mathrm{kg}$ of weight in sesame oil) for 3 days; the day after testosterone propionate administration, each rat received a single intraperitoneal injection of N-methyl-N-nitrosourea (MNU) at a dose of $50 \mathrm{mg} / \mathrm{kg}$ body weight in sterile saline, $\mathrm{pH} 5.0$. The cancer developed in the following 5 months and was evidenced at the end of this period through the histopathological study.

2.5. Experimental Design. A total of 40 rats were randomly assigned to 5 groups $(n=8)$. Group I: rats received NS (normal saline); Group II: rats were induced for prostate cancer with cyproterone, testosterone, and NMU; Groups III, IV, and V: rats were induced for cancer and received treatment with the flower extract of $C$. lutea daily in doses of 50,250 , and $500 \mathrm{mg} / \mathrm{kg}$ of body weight, respectively, starting after the induction of cancer and it was continued for 5 months. After the treatment period, rats were sacrificed by pentobarbital overdose and blood samples were collected for the serum determination of PSA and biochemical and 
hematological parameters. The prostate was dissected from the adherent connective tissue, washed several times with physiological solution, weighed exactly, and separated. The ventral lobe of the prostate was processed for histopathological examination.

2.6. Biochemical and Hematological Tests. Blood collection in rats was performed by intracardiac puncture; the animals were previously subjected to a state of general anesthesia (Ether chambers). Hematological tests were performed on a KT-6400 Automatic Hematology Analyzer (Genius ${ }^{\circledR}$, Med Equipment) and the biochemical tests were performed on an EMP-168 Model Semi-Automatic Biochemical Analyzer (Ivdiagnostik ${ }^{\circledR}$, Emperor Medical) according to the manufacturer's specifications.

Serum prostate-specific antigen (PSA) levels were quantified using the Chemiluminescence Immunoassay (CLIA) System, using the Maglumi 1000 (Snibe Diagnostic ${ }^{\circledR}$ ) equipment, following the manufacturer's specifications.

2.7. Histopathology Study. The fixed ventral prostate lobe was sequentially dissected and the samples embedded in paraffin and sectioned at $4 \mu \mathrm{m}$ were placed in the sheets and colored with Hematoxylin and Eosin. The histopathological study was performed by optical microscopy.

2.8. Statistical Analysis. Data were presented as mean \pm standard deviation. They were analyzed by one-way analysis of variance (ANOVA). The statistical significance between the means was determined by a post hoc Tukey test. The statistical software SPSS version 19 was used. Values of $P<0.05$ were considered statistically significant.

\section{Results}

3.1. Phytochemical Analysis of Ethanol Extract of Cordia lutea by GC/MS. The ethanolic extract of the Cordia lutea flower had a yield of $13.55 \%$. The spectra of the unknown components were compared to the spectrum of the known components stored in the NIST library. A total of four natural compounds were identified from flower's ethanol extract (Table 1). Retention Time (RT) for polar components varied between $29.99 \mathrm{~min}$ and $36.03 \mathrm{~min}$, including the major compounds gibberellic acid (31.67\%; RT: 15.75) and hexamethylcyclotrisiloxane (30.88\%; RT:36.03). The major compounds mentioned below and others with their RT, molecular formula (MF), and molecular weight (MW) were shown in Table 1.

3.2. Biochemical and Hematological Analysis. Table 2 showed that there was not significant decrease $(P>0.05)$ in RBC, WBC, Hemoglobin, Hematocrit, Neutrophils, Eosinophils, Basophils, Monocytes, Lymphocytes, and Platelets of the animals treated with Cordia lutea $(50,250$, and $500 \mathrm{mg} / \mathrm{Kg}$ ) when compared to the control group.
In Table 3, the result of serum liver and kidney function parameters of rats administered extract of Cordia lutea showed a significant decrease $(P<0.05)$ in aspartate aminotransferase (AST), alanine aminotransferase (ALT), and alkaline phosphatase (ALP) compared to the control animals. All other parameters tested were not significantly different in all the groups compared to control.

At all the doses tested, there were significant reductions $(P<0.05)$ in the triglycerides and LDL level of the rats compared to the control (Table 3). Animals in the 250 and $500 \mathrm{mg} / \mathrm{kg}$ groups witnessed significant increase $(P<0.05)$ in HDL-C concentration compared to the control group.

3.3. Morphological and Histopathology Study of Animals. The somatic prostate index (prostate volume/body weight $\times 100$ ) decreased with the treatment of Cordia lutea in a dose-dependent manner, being significant with the dose of 250 and $500 \mathrm{mg} / \mathrm{kg}$. The best effect occurred with the dose of $500 \mathrm{mg} / \mathrm{kg}$, where a decrease was observed from $0.34 \pm 0.04$ to $0.23 \pm 0.05(P<0.05)$ (Figure 1$)$. Serum PSA levels decreased significantly with the dose of 250 and $500 \mathrm{mg} / \mathrm{kg}$ (Figure 2).

Histopathological analysis will show a decrease in the number of layers, as well as high-grade prostatic intraepithelial neoplasia HG-PIN and low-grade prostatic intraepithelial neoplasia (LG-PIN). It was considered the best effect according to the evaluated doses (Table 4 and Figure 3).

\section{Discussion}

In the present investigation, the presence of gibberellic acid was found as chemical component, a compound that has not been reported by other researchers who rather found the presence of terpenic and phenolic compounds, such as flavonoids and leucoanthocyanidins, of which the majority compound was rutin [12].

Other research also reported the presence of rutin and quercetin in the whole plant as the main constituents [10]. This situation could be due to the method used in the investigation, since in our case the gas chromatography technique coupled to mass spectrometry (GC/MS) was used, while the presence of rutin and quercetin was determined by UPLC/MS.

The cancer-inducing model used in this study was able to produce an intraepithelial neoplasm, an infiltrating cancer that is divided into high grade and low grade; foci developed, reaching areas with hyperplasia and areas where there was a noticeable change with more than five layers. Treatment with Cordia lutea extract showed a favorable effect on the neoplastic process, evidenced by the reduction in the number of layers and high-grade prostatic intraepithelial neoplasia (HG-PIN), as well as low-grade prostatic intraepithelial neoplasia (LG-PIN) (Table 2 and Figure 3). Moreover, serum levels of PSA and somatic prostate index (prostate volume/ body weight of the rat) decreased significantly the effect of treatment with Cordia lutea (Figures 1 and 2). These results relate to the observed histopathologic changes. 
TABLE 1: Major components detected in the ethanol extract of Cordia lutea.

\begin{tabular}{lcccc}
\hline Name of compound & Retention time & Area (\%) & Molecular formula & Molecular weight \\
\hline Hexadecanoic acid, butyl ester & 29.99 & 5.89 & $\mathrm{C}_{20} \mathrm{H}_{40} \mathrm{O}_{2}$ & 118.17 \\
Butyl 9,12,15-octadecatrienoate & 31.71 & 4.29 & $\mathrm{C}_{22} \mathrm{H}_{38} \mathrm{O}_{2}$ & 312.53 \\
Gibberellic acid & 31.67 & 15.75 & $\mathrm{C}_{19} \mathrm{H}_{22} \mathrm{O}_{6}$ & 346.40 \\
Hexamethylcyclotrisiloxane & 36.03 & 30.88 & $\mathrm{C}_{6} \mathrm{H}_{18} \mathrm{O}_{3} \mathrm{Si}_{3}$ & 315.25 \\
\hline
\end{tabular}

${ }^{\mathrm{a}} \mathrm{RT}$ : retention time determined relative to a DB-5MS (5\% phenyl methyl silox). ${ }^{\mathrm{b}}$ Identification method: MS, comparison of mass spectra with those listed in the NIST11 and Wiley 9 libraries.

Table 2: Hematological parameters of rats induced with prostate cancer after treatment with Cordia lutea for 5 months.

\begin{tabular}{lccccc}
\hline Parameters & Control (NS) & Induced cancer & C. lutea $50 \mathrm{mg} / \mathrm{kg}$ & C. lutea $250 \mathrm{mg} / \mathrm{kg}$ & C. lutea $500 \mathrm{mg} / \mathrm{kg}$ \\
\hline RBC (x106/ul) & $6.13 \pm 0.79$ & $6.32 \pm 0.17$ & $6.12 \pm 0.34$ & $6.28 \pm 0.11$ & $6.24 \pm 0.13$ \\
WBC (x103/ul) & $7.24 \pm 0.51$ & $6.98 \pm 0.53$ & $7.17 \pm 0.30$ & $6.68 \pm 0.27$ & $6.72 \pm 0.43$ \\
Hemoglobin (g/dL) & $14.97 \pm 0.75$ & $15.15 \pm 0.23$ & $14.67 \pm 0.32$ & $15.13 \pm 0.31$ & $14.80 \pm 0.52$ \\
Hematocrit (\%) & $46.67 \pm 2.31$ & $48.33 \pm 1.53$ & $45.67 \pm 2.52$ & $47.67 \pm 1.53$ & $46.00 \pm 1.73$ \\
Neutrophils (\%) & $24.67 \pm 3.21$ & $24.33 \pm 3.51$ & $24.00 \pm 3.61$ & $26.33 \pm 4.93$ & $27.33 \pm 4.16$ \\
Eosinophils (\%) & $3.67 \pm 0.58$ & $4.00 \pm 1.00$ & $3.67 \pm 1.15$ & $3.33 \pm 1.53$ & $3.67 \pm 1.53$ \\
Basophils (\%) & $1.33 \pm 0.58$ & $1.67 \pm 0.58$ & $1.67 \pm 0.58$ & $1.67 \pm 0.58$ & $1.33 \pm 0.58$ \\
Monocytes (\%) & $4.33 \pm 1.53$ & $5.00 \pm 1.00$ & $4.00 \pm 1.00$ & $4.33 \pm 0.58$ & $4.67 \pm 1.15$ \\
Lymphocytes (\%) & $66.00 \pm 3.00$ & $65.00 \pm 4.36$ & $66.67 \pm 5.51$ & $64.33 \pm 3.79$ & $63.00 \pm 4.58$ \\
Platelets $\left(\times 10^{3} / \mathrm{ul}\right)$ & $534.00 \pm 24.25$ & $551.33 \pm 20.55$ & $560.00 \pm 20.00$ & $542.00 \pm 25.24$ & $541.00 \pm 11.53$ \\
\hline
\end{tabular}

Values are expressed as mean \pm SD, no significance when compared with control. RBC: red blood cell; WBC: white blood cell.

TABLE 3: Biochemical parameters of experimental groups treated with Cordia lutea for 5 months.

\begin{tabular}{lccccc}
\hline Parameters & Control (NS) & Induced cancer & C. lutea $50 \mathrm{mg} / \mathrm{kg}$ & C. lutea $250 \mathrm{mg} / \mathrm{kg}$ & C. lutea $500 \mathrm{mg} / \mathrm{kg}$ \\
\hline AST (IU/L) & $164.19 \pm 8.31$ & $199.01 \pm 7.76$ & $184.43 \pm 12.10$ & $175.40 \pm 7.55^{*}$ & $173.50 \pm 5.07^{*}$ \\
ALT (IU/L) & $66.63 \pm 3.46$ & $88.57 \pm 10.77$ & $85.63 \pm 7.40$ & $81.10 \pm 3.29$ & $78.80 \pm 12.39^{*}$ \\
Alkaline phosphatase (IU/L) & $311.2 \pm 11.15$ & $330.73 \pm 5.93$ & $320.60 \pm 17.17$ & $318.67 \pm 16.04^{*}$ & $316.43 \pm 9.68^{*}$ \\
Total bilirubin (mg/dL) & $0.71 \pm 0.07$ & $0.79 \pm 0.09$ & $0.75 \pm 0.05$ & $0.73 \pm 0.09$ & $0.73 \pm 0.05$ \\
Total protein (g/dL) & $6.80 \pm 0.14$ & $7.18 \pm 0.22$ & $7.11 \pm 0.24$ & $7.08 \pm 0.12$ & $6.98 \pm 0.19$ \\
Albumin (g/dL) & $3.96 \pm 0.12$ & $4.09 \pm 0.07$ & $3.90 \pm 0.06$ & $3.88 \pm 0.05$ & $3.93 \pm 0.11$ \\
Cholesterol (mg/dL) & $74.33 \pm 7.02$ & $89.33 \pm 7.77$ & $88.87 \pm 11.20$ & $87.73 \pm 9.40$ & $85.80 \pm 3.86$ \\
Triglycerides (mg/dL) & $107.00 \pm 7.94$ & $133.33 \pm 6.66$ & $129.67 \pm 5.51$ & $127.67 \pm 7.02$ & $120.87 \pm 8.95^{*}$ \\
HDL (mg/dL) & $31.00 \pm 1.73$ & $29.00 \pm 2.00$ & $30.83 \pm 3.68$ & $30.67 \pm 1.15$ & $32.67 \pm 2.08^{*}$ \\
LDL (mg/dL) & $21.93 \pm 7.31$ & $33.67 \pm 8.42$ & $32.10 \pm 12.18$ & $31.53 \pm 9.79$ & $28.96 \pm 6.94^{*}$ \\
Glucose (mg/dL) & $99.67 \pm 2.52$ & $97.00 \pm 5.29$ & $101.33 \pm 2.52$ & $104.33 \pm 7.37$ & $100.67 \pm 2.31$ \\
Urea (mg/dL) & $35.77 \pm 3.13$ & $39.13 \pm 2.68$ & $38.87 \pm 4.75$ & $41.80 \pm 4.61$ & $38.17 \pm 2.46$ \\
Creatinine (mg/dL) & $0.77 \pm 0.04$ & $0.84 \pm 0.06$ & $0.83 \pm 0.06$ & $0.84 \pm 0.05$ & $0.80 \pm 0.04^{*}$ \\
\hline
\end{tabular}

Values are mean \pm SD (expressed as mean \pm standard deviation), significance when compared with control * $(P<0.05)$. One-way ANOVA followed by Tukey's test. NS: normal saline; AST: aspartate aminotransferase; ALT: alanine aminotransferase; HDL: high-density lipoprotein; and LDL: low-density lipoprotein.

It has been reported that a large number of phytochemicals have anticancer properties, including polyphenols due to their free radical sequestration activity that confers antioxidant activity [18]. It is important to highlight the role of reactive oxygen species (ROS) in the activation of NF-kB and the subsequent transcription of more than 200 genes that suppress apoptosis and induce cell transformation, proliferation, invasion, metastasis, chemoresistance, radioresistance, and inflammation [19]. It has been shown that polyphenols can inhibit the growth of cancer cells by interacting with multiple signaling pathways, including those of NF-kB [20].

Various investigations have shown the anticancer effect of routine flavonoids and quercetin in several neoplasms.
Rutin induced apoptosis in HT-29 human colon cancer cells, mediated by the receptor and mitochondria-mediated apoptotic pathways [21]. Likewise, it produced an antineuroblastoma effect via the arrest of the cell cycle progression in the G2/M phase and also induced cell apoptosis as well as the regulation of apoptosis-related genes [22]. Rutin, via nonselective inhibition of P-glycoprotein (Pgp) and breast cancer resistance protein pump (BCRP), efficiently reverses multidrug resistance and restores chemosensitivity to cyclophosphamide and successfully stops cell cycle progression [23].

It also significantly inhibited the progression of human hepatocellular carcinoma HEPG2 cells, was remarkably effective on migration, colony formation, and invasive 


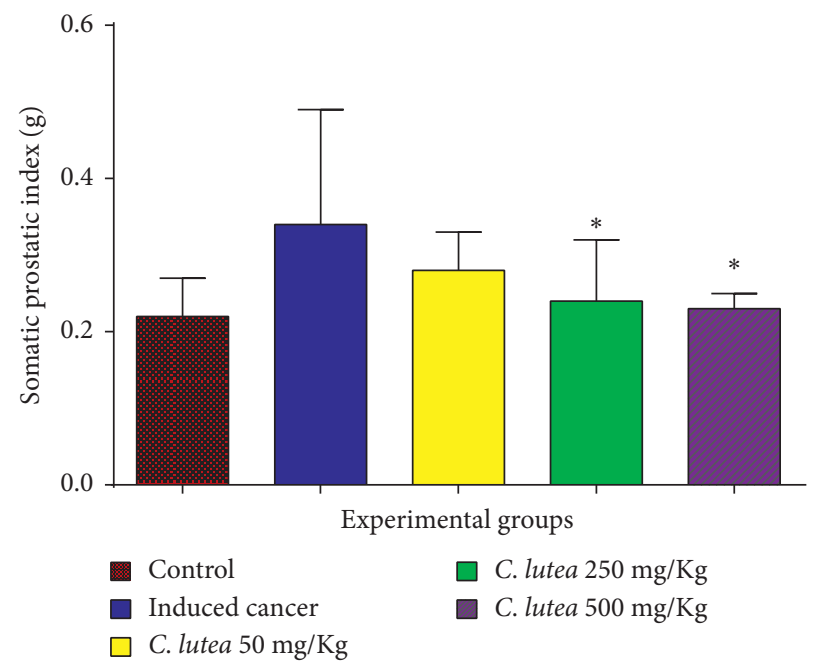

Figure 1: Somatic prostate index in rats with induced prostate cancer after 5 months of treatment with Cordia lutea. ${ }^{*}(P<0.05)$ vs. induced cancer group.

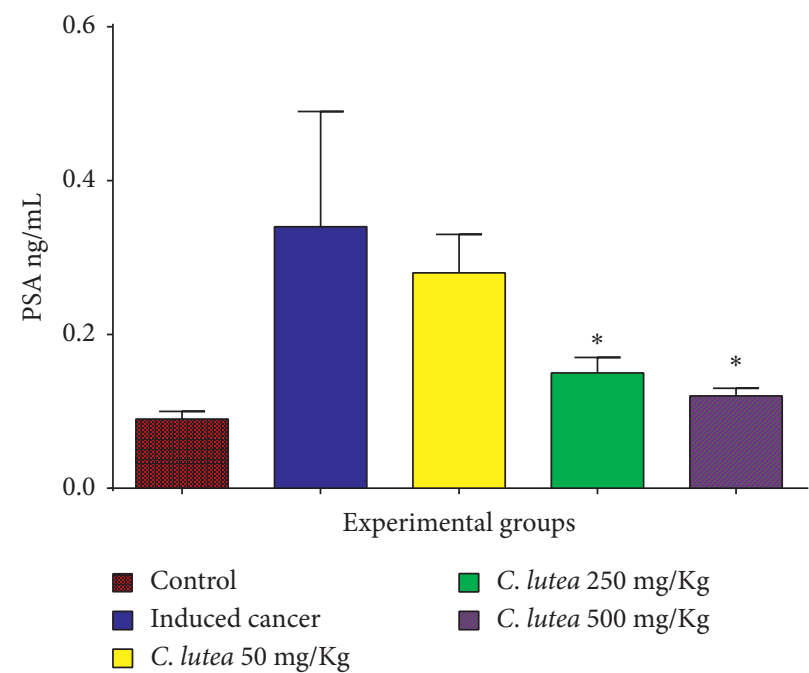

FIgURE 2: PSA levels in rats with induced prostate cancer after 5 months of treatment with Cordia lutea. ${ }^{*}(P<0.05)$ vs. induced cancer group.

TABLE 4: Histopathological analysis of prostate tissue in rats with prostate cancer and treated with Cordia lutea for 5 months.

\begin{tabular}{|c|c|c|c|c|c|}
\hline Group & Lumen & Epithelium & Layers & LG-PIN & HG-PIN \\
\hline NS & Regular & Cubic & 1 & Negative & Negative \\
\hline Induced cancer & Papillary & Columnar & $>5$ & Positive $++/+++$ & Positive $++/+++$ \\
\hline Cordia lutea $50 \mathrm{mg} / \mathrm{kg}$ & Papillary & Columnar & $2-3$ & Positive $++/+++$ & Positive $+/+++$ \\
\hline Cordia lutea $250 \mathrm{mg} / \mathrm{kg}$ & Papillary & Columnar & $2-3$ & Positive $+/+++$ & Negative \\
\hline Cordia lutea $500 \mathrm{mg} / \mathrm{kg}$ & Papillary & Columnar & $1-2$ & Negative & Negative \\
\hline
\end{tabular}

NS = normal saline. HG-PIN = high-grade prostatic intraepithelial neoplasia. LG-PIN = low-grade prostatic intraepithelial neoplasia.

potential of HEPG2 cells, and increased apoptosis. In addition, rutin was found to be a potent CYP3A4 inhibitor and activator of CYP1A1 and of antioxidant enzymes glutathione S-transferases (GSTs) and NADPH quinone oxidoreductase I (NQO1) [24]. Furthermore, high-dose quercetin reduced colorectal carcinogenesis in rats; it is noteworthy to mention that this flavonoid has many intracellular targets in the treatment of cancer including proteins involved in apoptosis, cell cycle, detoxification, antioxidant, replication, and angiogenesis $[25,26]$. The flavonoids quercetin and 

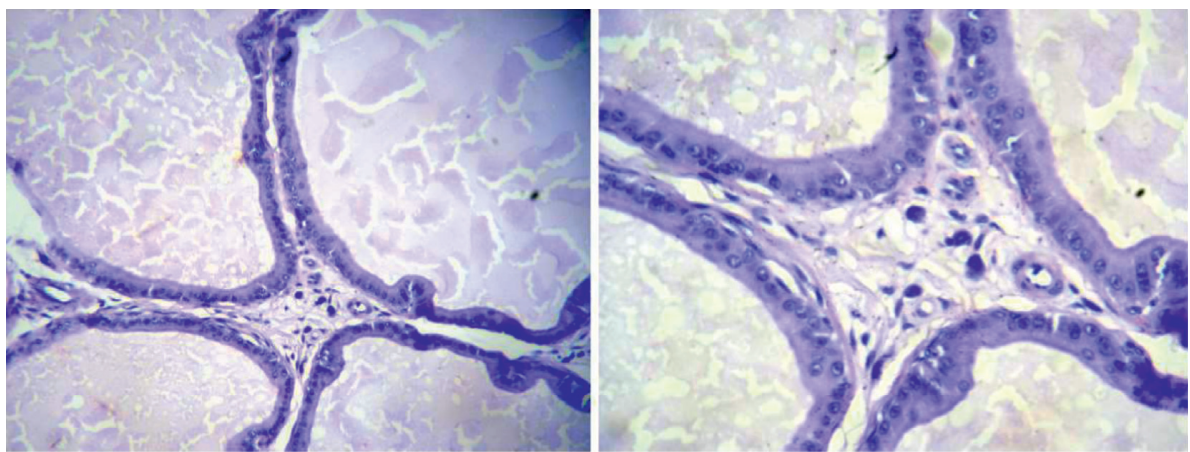

(a)

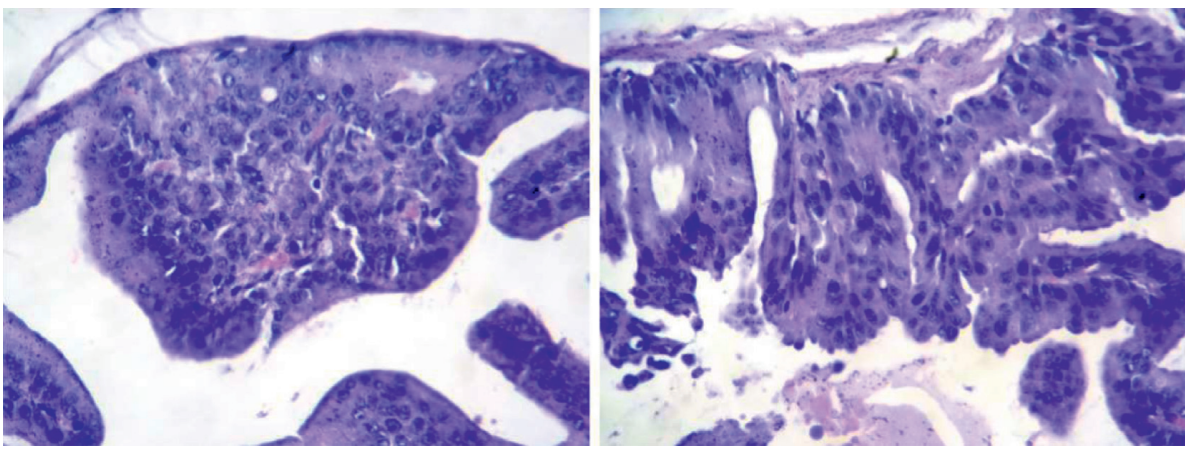

(b)

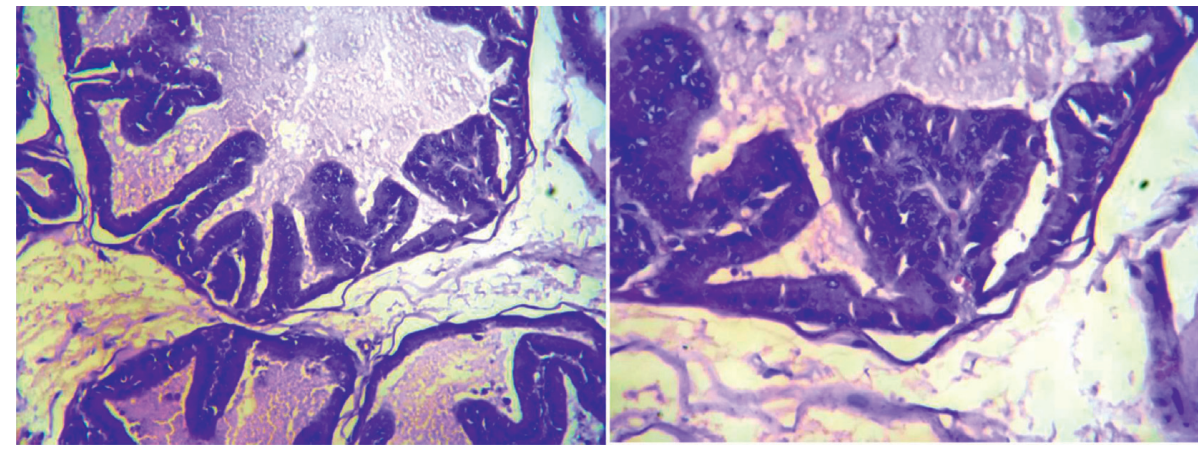

(c)

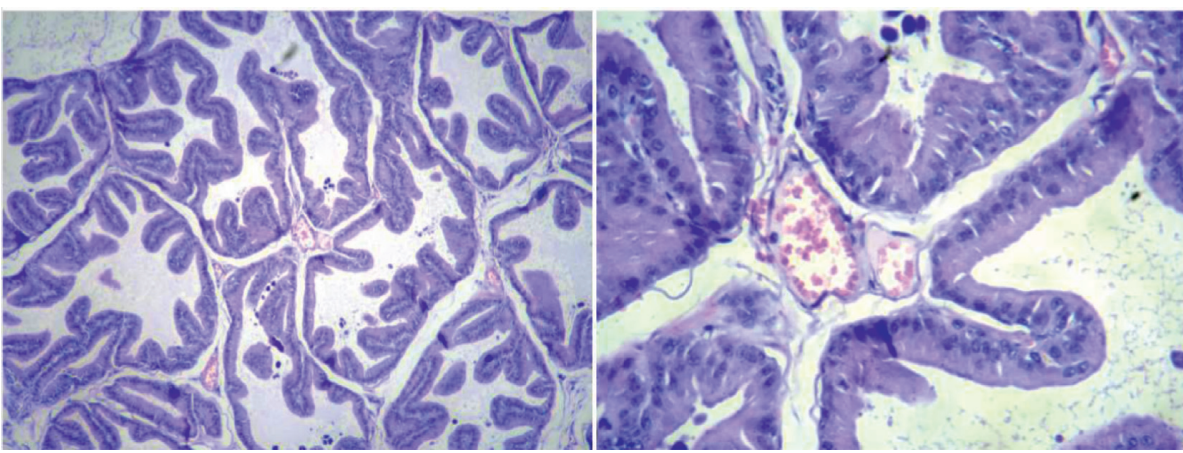

(d)

Figure 3: Continued. 


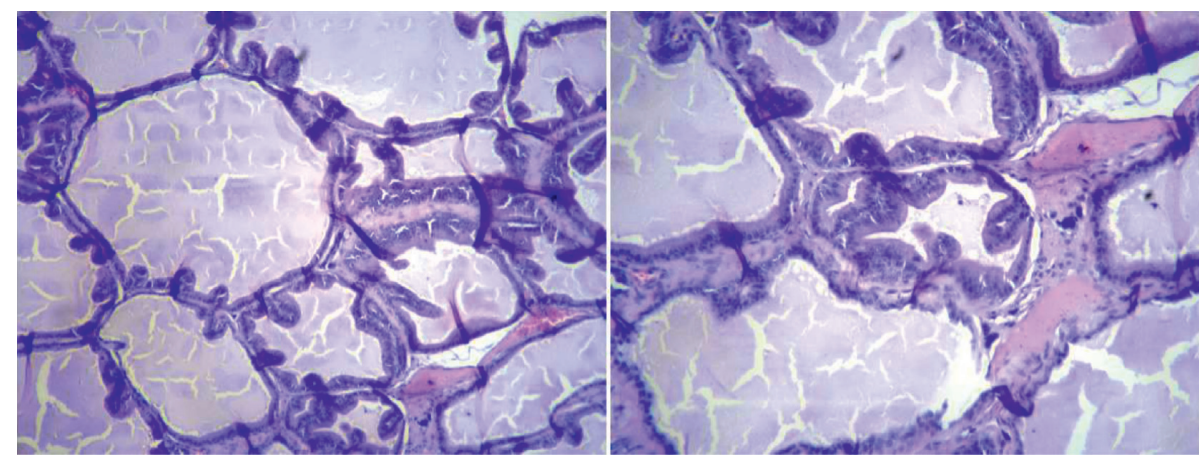

(e)

FIgURE 3: Microphotography of rat's prostate stained with Hematoxylin and Eosin (H\&E), at $10 \mathrm{X}$ and $40 \mathrm{X}$ magnification. (a) Physiological saline $2 \mathrm{~mL} / \mathrm{kg}$. Normal. Cubic cells, not columnar. (b) Prostate tissue with induced cancer. Many layers are observed, cells in mitosis; large number of cells with high-grade prostatic intraepithelial neoplasia (HG-PIN) and low-grade prostatic intraepithelial neoplasia (LG-PIN). (c) Cordia lutea $50 \mathrm{mg} / \mathrm{kg}$, intraepithelial neoplasia of low and somewhat grade is observed. (d) Cordia lutea $250 \mathrm{mg} / \mathrm{kg}$, basically hyperplasia is observed, high- and low-grade foci are not reached. (e) Induced + Cordia lutea $500 \mathrm{mg} / \mathrm{kg}$, hyperplasia is observed; it remains in hyperplasia; it does not reach high-grade or low-grade foci.

rutin showed antiangiogenic activity in the chorioallantoic membrane model and antioxidant and anticancer activity [27].

One study has reported that in prostate cancer cells, quercetin can exert its chemopreventive effect by 3 mechanisms: (a) inhibiting the activity of CYP1A1 and CYP1B1 (overexpressed in human cancer cells) and therefore reducing the formation of mutagenic intermediates and carcinogens of polycyclic aromatic hydrocarbons (PAHs), heterocyclic amines, and estradiol; (b) regulating the high peroxiredoxin 3 (Prx III), thereby reducing intracellular $\mathrm{H}_{2} \mathrm{O}_{2}$ levels leading to cell proliferation inhibition; and (c) counteracting the effects mediated by the ubiquitous environmental contaminant benzo[a]pyrene $(\mathrm{BaP})$, whose exposure is associated with prostate carcinogenesis, on Prx I and Prx II peroxiredoxins or interacting directly with ROS mediated by $\mathrm{BaP}$ and preventing oxidative damage [28].

\section{Conclusion}

In conclusion, under the experimental conditions the ethanolic extract of Cordia lutea has chemopreventive effect on NMU-induced prostate cancer in rats. It is likely that flavonoids quercetin and rutin in the extract of Cordia lutea, for its anti-inflammatory, antiangiogenic, apoptotic, and antioxidant properties, are partly responsible for the antineoplastic effect observed in this study.

\section{Abbreviations}

NMU: N-Methyl-N-nitrosourea

EECL: $\quad$ Ethanolic extract of Cordia lutea

NF-kB: Nuclear factor kappa-light-chain-enhancer of activated B cells

ANOVA: Analysis of variance

NS: $\quad$ Normal saline

HG-PIN: High-grade prostatic intraepithelial neoplasia

LG-PIN: Low-grade prostatic intraepithelial neoplasia.

\section{Data Availability}

All data used to support the findings of this study can be made available from the corresponding author upon request (oherreraca@unmsm.edu.pe).

\section{Conflicts of Interest}

The authors declare that they have no conflicts of interest regarding the publication of this paper.

\section{Authors' Contributions}

Juan Pedro Rojas-Armas and Jorge Luis Arroyo-Acevedo designed the study. Oscar Herrera-Calderon, Agustín RojasArmas, Miriam Palomino-Pacheco, and Hugo Justil-Guerrero conducted the experiments. Juan Pedro Rojas-Armas, and Oscar Herrera-Calderon wrote the manuscript. Julio Hilario-Vargas plotted the manuscript. Juan Manuel OrtizSanchez, James Calva, and Américo Castro-Luna revised the manuscript. All authors approved the final version of the manuscript.

\section{Acknowledgments}

The authors thank "Vicerrectorado de Investigación y Posgrado" (VRIP) from the Universidad Nacional Mayor de San Marcos (Lima, Peru) for giving us the support and facilities to carry out this work (06343-RR-17; project code A17010052).

\section{References}

[1] World Health Organization, Cancer Overview, 2020, https:// www.who.int/health-topics/cancer\#tab=tab_1.

[2] R. A. Nugent, M. J. Husain, D. Kostova, and F. Chaloupka, "Introducing the PLOS special collection of economic cases for NCD prevention and control: a global perspective," PLoS One, vol. 15, no. 2, Article ID e0228564, 2020. 
[3] World Health Organization, WHO Report on Cancer: Setting Priorities, Investing Wisely and Providing Care for All, World Health Organization, Geneva, Switzerland, 2020.

[4] R. L. Siegel, K. D. Miller, and A. Jemal, "Cancer statistics, 2020," CA: A Cancer Journal for Clinicians, vol. 70, no. 1, pp. 7-30, 2020.

[5] J. S. Torres-Roman, E. F. Ruiz, J. F. Martinez-Herrera et al., "Prostate cancer mortality rates in Peru and its geographical regions," BJU International, vol. 123, no. 4, pp. 595-601, 2019.

[6] A. Bayraktar-Ekincioglu, K. Demirkan, B. Keskin, O. Aslantas, and E. Ozdemir, "Potential drug interactions and side effects in an outpatient oncology clinic: a retrospective descriptive study," European Journal of Hospital Pharmacy, vol. 21, no. 4, pp. 216-221, 2014.

[7] T. Sivabalan, "A study to assess the side effects and coping strategies adopted by cancer patients receiving chemotherapy treatment," International Journal of Nursing Education, vol. 5, no. 1, pp. 204-207, 2013.

[8] K. Ivanova and M. Avota, "Antineoplastic drugs: occupational exposure and side effects," Proceedings of the Latvian Academy of Sciences. Section B. Natural, Exact, and Applied Sciences.vol. 70, no. 5, pp. 325-329, 2016.

[9] R. O. Fourcade, A. Benedict, L. K. Black, M. E. Stokes, A. Alcaraz, and R. Castro, "Treatment costs of prostate cancer in the first year after diagnosis: a short-term cost of illness study for France, Germany, Italy, Spain and the UK," BJU International, vol. 105, pp. 49-56, 2009.

[10] I. Mayevych, J. M. López-Romero, and J. Cabanillas, "Chemical composition of Cordia lutea L.: absence of pyrrolizidine alkaloids," Natural Products Chemistry and Research, vol. 3, p. 194, 2015.

[11] R. W. Bussmann and A. Glenn, "Medicinal plants used in Northern Peru for reproductive problems and female health," Journal of Ethnobiology and Ethnomedicine, vol. 6, no. 1, p. 30, 2010.

[12] L. Medina and K. Vásquez, Estudio farmacognóstico y cuantificación de flavonoides totales de las flores de Cordia lútea (flor de overo) proveniente de Cormot distrito de Compin provincia de Gran Chimu Región La Libertad, Tesis. UNT, Trujillo, Peru, 2015.

[13] F. Khan, K. Niaz, F. Maqbool et al., "Molecular targets underlying the anticancer effects of quercetin: an update," Nutrients, vol. 8, no. 529, pp. 1-19, 2016.

[14] J. Calva, N. Bec, G. Gilardoni et al., "Acorenone B: AChE and $\mathrm{BChE}$ inhibitor as a major compound of the essential oil distilled from the ecuadorian species niphogeton dissecta," Pharmaceuticals, vol. 10, no. 4, p. 84, 2017.

[15] National Research Council, Guide for the Care and Use of Laboratory Animals, The National Academies Press, Washington, DC, USA, 8th edition, 2011, https:/grants.nih.gov/grants/olaw/ Guide-for-the-Care-and-use-of-laboratory-animals.pdf.

[16] G. Sharmila, T. Athirai, B. Kiruthiga et al., "Chemopreventive effect of quercetin in MNU and testosterone induced prostate cancer of sprague-dawley rats," Nutrition and Cancer, vol. 66, no. 1, pp. 38-46, 2014.

[17] S. Banudevi, P. Elumalai, R. Arunkumar et al., "Chemopreventive effects of zinc on prostate carcinogenesis induced by $\mathrm{N}$-methyl-N-nitrosourea and testosterone in adult male sprague-dawley rats," Journal of Cancer Research and Clinical Oncology, vol. 137, no. 4, pp. 677-686, 2011.

[18] J. Oh, L. Hlatky, Y.-S. Jeong, and D. Kim, “Therapeutic effectiveness of anticancer phytochemicals on cancer stem cells," Toxins, vol. 8, no. 7, p. 199, 2016.
[19] A. R. Khuda-Bukhsh, S. Das, and S. K. Saha, "Molecular approaches toward targeted cancer prevention with some food plants and their products: inflammatory and other signal pathways," Nutrition and Cancer, vol. 66, no. 2, pp. 194-205, 2014.

[20] M. Fantini, M. Benvenuto, L. Masuelli et al., "In vitro and in vivo antitumoral effects of combinations of polyphenols, or polyphenols and anticancer drugs: perspectives on cancer treatment," International Journal of Molecular Sciences, vol. 16, no. 12, pp. 9236-9282, 2015.

[21] T. E. Guon and H. S. Chung, "Hyperoside and rutin of Nelumbo nucifera induce mitochondrial apoptosis through a caspase-dependent mechanism in HT-29 human colon cancer cells," Oncology Letters, vol. 11, no. 4, pp. 2463-2470, 2016.

[22] H. Chen, Q. Miao, M. Geng et al., "Anti-tumor effect of rutin on human neuroblastoma cell lines through inducing G2/M cell cycle arrest and promoting apoptosis," The Scientific World Journal, vol. 2013, pp. 1-8, 2013.

[23] M. Iriti, R. Kubina, A. Cochis et al., "Rutin, a quercetin glycoside, restores chemosensitivity in human breast cancer cells," Phytotherapy Research, vol. 31, no. 10, pp. 1529-1538, 2017.

[24] S. Karakurt, "Modulatory effects of rutin on the expression of cytochrome P450s and antioxidant enzymes in human hepatoma cells," Acta Pharmaceutica, vol. 66, no. 4, pp. 491-502, 2016.

[25] A. A. Dihal, V. C. J. de Boer, H. van der Woude et al., "Quercetin, but not its glycosidated conjugate rutin, inhibits azoxymethane-induced colorectal carcinogenesis in F344 rats," The Journal of Nutrition, vol. 136, no. 11, pp. 2862-2867, 2006.

[26] D. Kashyap, S. Mittal, K. Sak, P. Singhal, and H. S. Tuli, "Molecular mechanisms of action of quercetin in cancer: recent advances," Tumor Biology, vol. 37, no. 10, pp. 12927-12939, 2016.

[27] R. N. Gacche, H. D. Shegokar, D. S. Gond, Z. Yang, and A. D. Jadhav, "Evaluation of selected flavonoids as antiangiogenic, anticancer, and radical scavenging agents: an experimental and in silico analysis," Cell Biochemistry and Biophysics, vol. 61, no. 3, pp. 651-663, 2011.

[28] A. M. Chaudhary, Mechanistic Analysis of Cancer Chemopreventative Flavonoids and Benzo [a] Pyrene in Prostate Cancer Cells, University of Mississippi, Oxford, MS, USA, 2006. 